Article

\title{
Effect of Nitrogen Flow in Hydrogen/Nitrogen Plasma Annealing on Aluminum-Doped Zinc Oxide/Tin-Doped Indium Oxide Bilayer Films Applied in Low Emissivity Glass
}

\author{
Shang-Chou Chang $1,2, * \mathbb{C}$ and Huang-Tian Chan ${ }^{2}$ \\ 1 Department of Electrical Engineering, Kun Shan University, No.195, Kunda Road, Yong-kang District, \\ Tainan City 71070, Taiwan \\ 2 Green Energy Technology Research Center, Kun Shan University, No.195, Kunda Road, \\ Yong-kang District, Tainan City 71070, Taiwan; g5eek79@gmail.com \\ * Correspondence: jchang@mail.ksu.edu.tw; Tel.: +886-6-2051512
}

Received: 28 May 2019; Accepted: 13 June 2019; Published: 17 June 2019

\begin{abstract}
Low emissivity glass (low-e glass), which is often used in energy-saving buildings, has high thermal resistance and visible light transmission. Heavily doped wide band gap semiconductors like aluminum-doped zinc oxide (AZO) and tin-doped indium oxide (ITO) have these properties, especially after certain treatment. In our experiments, in-line sputtered AZO and ITO bilayer (AZO/ITO) films on glass substrates were prepared first. The deposition of AZO/ITO films was following by annealing in hydrogen/nitrogen $\left(\mathrm{H}_{2} / \mathrm{N}_{2}\right)$ plasma with different $\mathrm{N}_{2}$ flows. The structure and optical and electrical properties of AZO/ITO films were surveyed. Experiment results indicated that $\mathrm{N}_{2}$ flow in $\mathrm{H}_{2} / \mathrm{N}_{2}$ plasma annealing of AZO/ITO films slightly modified the structure and electrical properties of AZO/ITO films. The X-ray diffraction peak corresponding to zinc oxide (002) crystal plane slightly shifted to a higher angle and its full width at half maximum decreased as the $\mathrm{N}_{2}$ flow increased. The electrical resistivity and the emissivity reduced for the plasma annealed AZO/ITO films when the $\mathrm{N}_{2}$ flow was raised. The optimum $\mathrm{H}_{2} / \mathrm{N}_{2}$ gas flow was $100 / 100$ for plasma annealed AZO/ITO films in this work for low emissivity application. The emissivity and average visible transmittance for $\mathrm{H}_{2} / \mathrm{N}_{2}=100 / 100$ plasma annealed $\mathrm{AZO} / \mathrm{ITO}$ were 0.07 and $80 \%$, respectively, lying in the range of commercially used low emissivity glass.
\end{abstract}

Keywords: $\mathrm{H}_{2} / \mathrm{N}_{2}$ plasma; AZO/ITO; low emissivity glass

\section{Introduction}

Low emissivity glass (low-e glass), which owns characteristics of high visible transmittance and infrared reflectance, has been popularly applied in energy-saving architecture [1,2]. Two kinds of low emissivity glass exist: metal-based multilayers and heavily doped wide energy gap semiconductors are reported in the market [3,4]. Silver is the most often used metal for metal-based multilayers. The film thickness of silver must be carefully controlled to possess highly both visible transmittance and infrared reflectance [5]. However, silver is easily oxidized and undergoes poor adhesion with a glass substrate. Some protection and interface layers are usually added on and below the silver films on the glass substrate. Single-layer silver-based multilayer low emissivity glass has at least five layers of films, while double-layer silver ones have more than eight layers [6]. Multilayer film preparation increases production cost. Heavily doped wide energy gap semiconductors which do not need many layers and which may be considered as a substitute for silver-based multilayers applied in low emissivity glass were investigated in this work. 
Aluminum-doped zinc oxide (AZO) and tin-doped indium oxide (ITO) are heavily doped wide energy gap semiconductors. Owing to the favorable optical and electrical properties of ITO and AZO $[7,8]$, they are commonly applied in solar cells, organic light-emitting diodes, and energy-saving glass, etc. [9-12]. The Hagen-Rubens relation states emissivity of materials decreases when lowering their electrical resistivity [13]. Recent studies have shown that post treatment could reduce electrical resistivity and increase the visible transmission of ITO and/or AZO films [14-19]. The reduction of electrical resistivity of $\mathrm{AZO}$ for $\mathrm{H}_{2}$ plasma treatment possibly results from desorption of oxygen from the grain boundary or the formation of a complex (such as $\mathrm{Zn}-\mathrm{H}$ ) [14-16]. Muthitamongkol et al. have reported that a decrease in electrical resistivity of AZO films with Ar plasma treatment may be attributed to the conversion of the crystal structure orientation [18]. Wu et al. have reported that a reduction in electrical resistivity for $\mathrm{H}_{2} / \mathrm{Ar}$ plasma possibly resulted from reducing negatively-charged oxygens adsorbed on the surface of the grain boundary and providing shallow donor states produced by doped hydrogens [19].

Our research team has fabricated ITO films post-annealed at different $\mathrm{H}_{2} / \mathrm{N}_{2}$ flows [20]. We have found that optimized $\mathrm{H}_{2} / \mathrm{N}_{2}$ annealing on ITO can reduce the electrical resistivity of ITO films $58 \%$ more than that with pure $\mathrm{H}_{2}$ annealing. This could be related to the high thermal conductivity of $\mathrm{H}_{2}$, which is seven times that of $\mathrm{N}_{2}$ [21]. Plasma energy can be readily dissipated by this high thermal conductivity media during plasma treatment on ITO.

This work investigated the structure, electrical, and optical properties of AZO/ITO films. The AZO/ITO films on glass were prepared by in-line sputtering. Later, the AZO/ITO films were post-annealed in $\mathrm{H}_{2} / \mathrm{N}_{2}$ plasma at different $\mathrm{H}_{2} / \mathrm{N}_{2}$ flow ratios $(100 / 0,100 / 50$, and $100 / 100)$. The results indicate that the structure of AZO/ITO films can be modified by $\mathrm{H}_{2} / \mathrm{N}_{2}$ plasma annealing. The structure and electrical and optical properties of the AZO/ITO films were surveyed. The optimized flow ratio in $\mathrm{H}_{2} / \mathrm{N}_{2}$ plasma annealing was obtained from the analysis of the measured results.

\section{Materials and Methods}

The AZO/ITO films were prepared on glass substrates by in-line sputtering. The film thickness of both AZO and ITO was $250 \mathrm{~nm}$. The substrate was not intentionally heated during sputtering. The sputtering target of $\mathrm{AZO}$ was $\mathrm{ZnO}: \mathrm{Al}_{2} \mathrm{O}_{3}=98: 2 \mathrm{wt} . \%$ in composition and $760 \times 136 \mathrm{~mm}^{2}$ in size. The AZO layer was sputtered using a pure Ar flow of $440 \mathrm{sccm}$, a working pressure of $3 \times 10^{-3}$ Torr, and a sputtering power of $2 \mathrm{~kW}$. The sputtering target of ITO was with $\mathrm{In}_{2} \mathrm{O}_{3}: \mathrm{SnO}_{2}=90: 10 \mathrm{wt} . \%$ in composition and $150 \times 1500 \mathrm{~mm}^{2}$ in size. The ITO layer was sputtered under an $\operatorname{Ar}(85 \%) / \mathrm{O}_{2}(15 \%)$ flow of $40 \mathrm{sccm}$, a working pressure of $1.6 \times 10^{-3}$ Torr, and a sputtering power of $9 \mathrm{~kW}$. The glass substrate was rinsed by ultrasonic treatment in acetone, isopropyl alcohol, and pure water sequentially. After that, the glass was dried with dry $\mathrm{N}_{2}$.

The AZO/ITO films were plasma annealed with different $\mathrm{H}_{2} / \mathrm{N}_{2}$ flow ratios of $100 / 0,100 / 50$, and 100/100, and were named samples S1, S2, and S3, respectively. Other process parameters used in $\mathrm{H}_{2} / \mathrm{N}_{2}$ plasma treatment were 25 Torr in gas pressure, $600 \mathrm{~W}$ in plasma power and $5 \mathrm{~min}$ in process time.

The microstructure and electrical, optical, and emissivity properties of the $\mathrm{H}_{2} / \mathrm{N}_{2}$ plasma annealed AZO/ITO films were investigated. The crystalline structure and surface morphologies of the AZO/ITO films were explored separately using an X-ray diffractometer (D/MAX-2500 V, Rigaku, Tokyo, Japan) and a scanning electron microscope (SU8000, HITACHI, Tokyo, Japan). Hall measurements (Ecopia HMS-3000, Ecopia, Gyeonggi-do, South Korea) were made in order to deduce the carrier concentration, mobility, and electrical resistivity of the AZO/ITO films. The visible optical transmittance of the AZO/ITO films was surveyed with a UV/VIS/NIR spectrophotometer (PerkinElmer LAMBDA 750, PerkinElmer, Waltham, USA) in the $380 \sim 780 \mathrm{~nm}$ range. The emissivity of the AZO/ITO films was obtained using an emissivity meter (TSS-5X, Japan Sensor, Tokyo, Japan). 


\section{Results and Discussions}

Figure 1 shows scanning electron micrographs of S1, S2, and S3, respectively. The crystal grains of the AZO/ITO films are shown to grow with increasing $\mathrm{N}_{2}$ flow.

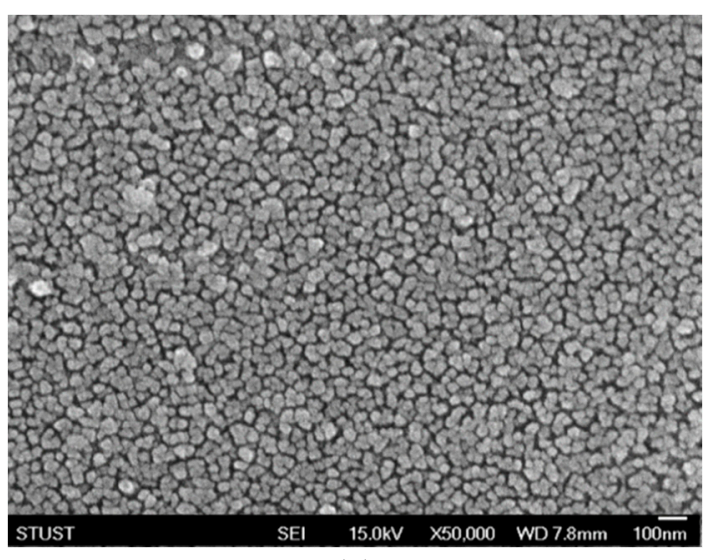

(a)

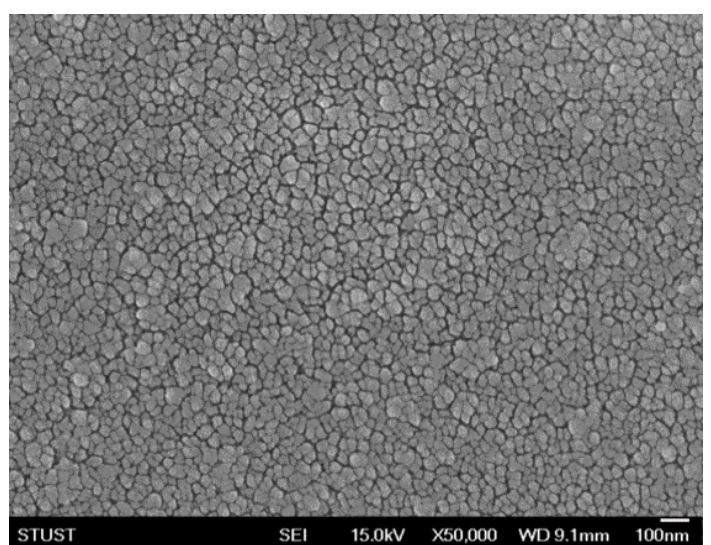

(b)

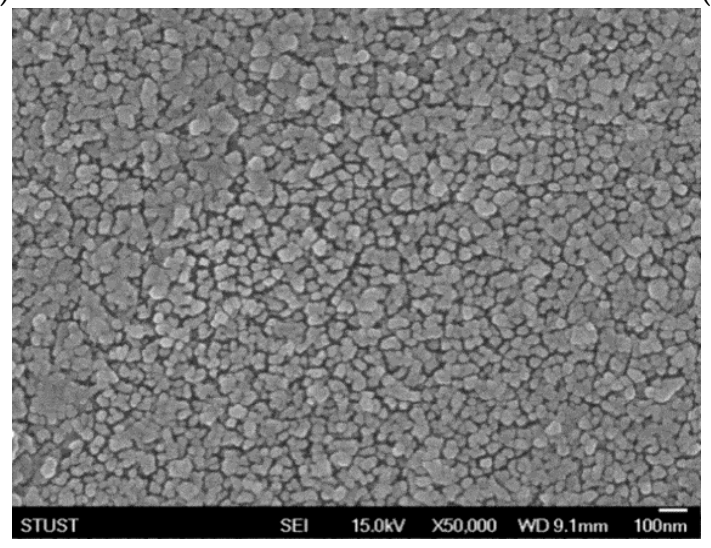

(c)

Figure 1. Scanning electron micrographs of the $\mathrm{H}_{2} / \mathrm{N}_{2}$ plasma processed aluminum-doped zinc oxide (AZO)/tin-doped indium oxide (ITO) films at gas ratios of (a) 100/0, (b) 100/50, and (c) 100/100.

X-ray diffractometer patterns of S1, S2, and S3 are presented in Figure 2, in which two peaks corresponding to the (002) of $\mathrm{ZnO}$ and the (222) of ITO may be observed. The peak with respect to (002) of $\mathrm{ZnO}$ is seen to slightly shift to a higher angle and its full width at half maximum (FWHM) decreases with increasing $\mathrm{N}_{2}$ flow.

The (002) peak of $\mathrm{ZnO}$ shifting towards a slightly higher angle implies that the distance between the (002) crystal planes of $\mathrm{ZnO}$ is decreasing. This phenomenon may be the result of replacing the $\mathrm{Zn}$ ions with $\mathrm{Al}$ ions [22]. Zinc ions have an ionic radius of $0.74 \AA$, which is similar to but a little bigger than the radius of $\mathrm{Al}$ ions, which is $0.50 \AA$ [23]. The Scherrer equation points out that the grain size of materials increases when the FWMH of the X-ray diffraction peak reduces for the corresponding materials [24]. The FWHM of the (002) peak for $\mathrm{ZnO}$ narrows with increasing $\mathrm{N}_{2}$ flow during $\mathrm{H}_{2} / \mathrm{N}_{2}$ plasma annealing, as shown in Figure 2, indicating that the grain size of the $\mathrm{H}_{2} / \mathrm{N}_{2}$ plasma annealed AZO/ITO films increases with $\mathrm{N}_{2}$ flow during annealing deduced from the Scherrer equation, which is in agreement with the results of the SEM micrographs observed in Figure 1. 


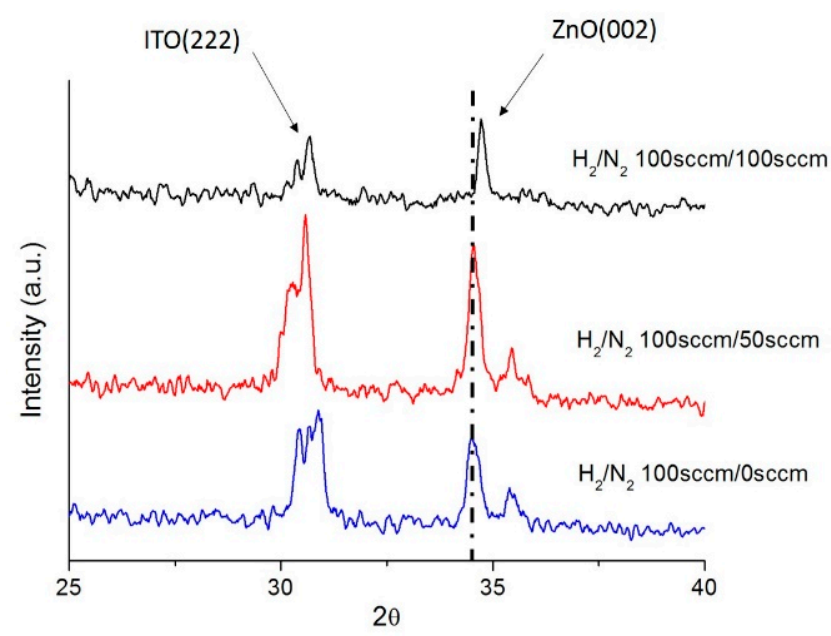

Figure 2. $\mathrm{XRD}$ patterns of the $\mathrm{H}_{2} / \mathrm{N}_{2}$ plasma processed $\mathrm{AZO} / \mathrm{ITO}$ films.

The electrical properties of the plasma annealed AZO/ITO films were also investigated. In Figure 3 it is evident that the electrical resistivity of the AZO/ITO films decreases and the carrier concentration of AZO/ITO films increases with $\mathrm{N}_{2}$ flow. Sample S3 had the lowest resistivity, $2.89 \times 10^{-4} \Omega$-cm, out of $\mathrm{S} 1, \mathrm{~S} 2$, and S3. The mobility of S1, S2, and S3 was $19.2,25.0$, and $23.2 \mathrm{~cm}^{2} / \mathrm{Vs}$, respectively.

The reducing electrical resistivity of the AZO/ITO films with increasing $\mathrm{N}_{2}$ flow during the $\mathrm{H}_{2} / \mathrm{N}_{2}$ plasma process could result from replacing $\mathrm{Zn}$ ions with $\mathrm{Al}$ ions and the increase in grain size of the AZO/ITO films. Electrical resistivity of the materials is inversely proportional to the product of carrier concentration and mobility. The XRD diffraction peak corresponding to the (002) ZnO crystal plane slightly shifting to a higher angle, as observed from Figure 2, hints at the replacement of $\mathrm{Zn}$ ions with $\mathrm{Al}$ ions for the AZO/ITO films. The replacement increases the carrier concentration of the AZO/ITO films, which agrees with the measured results of carrier concentration in Figure 3 . The mobility of the materials increases with decreasing defects of the materials. The measured grain size and the carrier concentration of the AZO/ITO films increasing with $\mathrm{N}_{2}$ flow during the $\mathrm{H}_{2} / \mathrm{N}_{2}$ plasma process can be observed in Figure 1; Figure 3, respectively. An increase in grain size reduced surface defects and an increase in carrier concentration increased point defects in the AZO/ITO films. This could explain why the mobility of the $\mathrm{H}_{2} / \mathrm{N}_{2}$ plasma annealed AZO/ITO films reached a maximum at $\mathrm{H}_{2} / \mathrm{N}_{2}=100 / 50$, not at $100 / 100$.

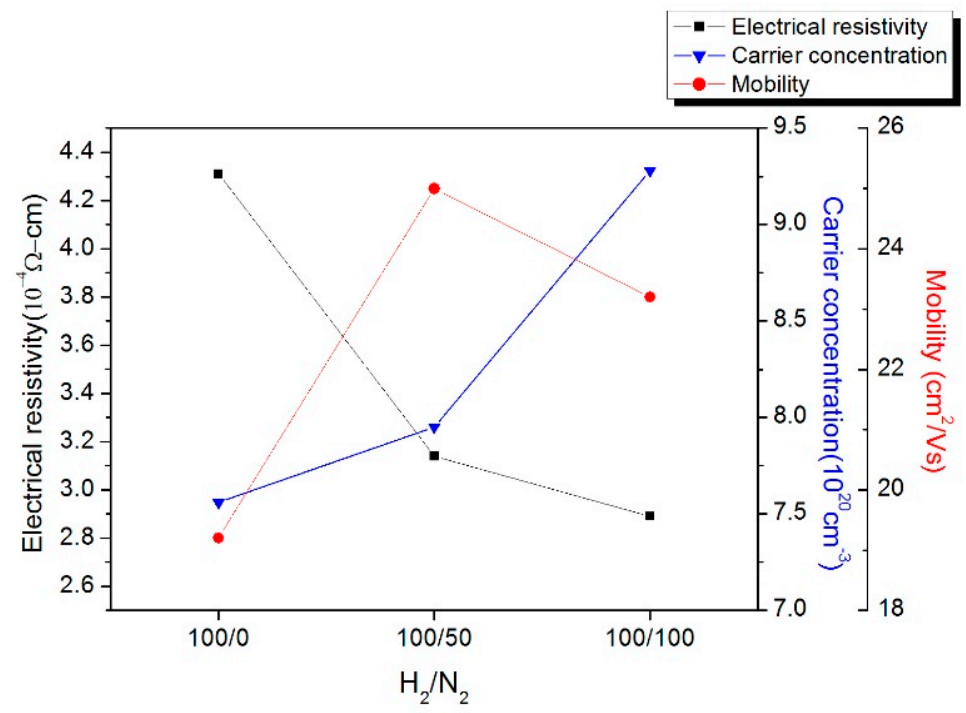

Figure 3. Electrical properties of the $\mathrm{H}_{2} / \mathrm{N}_{2}$ plasma processed $\mathrm{AZO} / \mathrm{ITO}$ films. 
Table 1 shows the emissivity and average transmittance in visible light of the $\mathrm{H}_{2} / \mathrm{N}_{2}$ plasma annealed AZO/ITO films. Figure 4 reveals the transmission spectra of the AZO/ITO films by plasma treatment. The average transmittance in the visible region $(380-780 \mathrm{~nm})$ for $\mathrm{S} 1, \mathrm{~S} 2$, and $\mathrm{S} 3 \mathrm{was} 80 \%$. The emissivity of the AZO/ITO films decreased with increasing $\mathrm{N}_{2}$ flow. The emissivity of S1, S2, and S3 was $0.10,0.08$, and 0.07 , respectively. The emissivity of the materials decreased with their electrical resistivity according to the Hagen-Rubens relation [13]. The electrical resistivity of the AZO/ITO films decreased (Figure 3) and the emissivity of the $\mathrm{H}_{2} / \mathrm{N}_{2}$ AZO/ITO films also decreased (Table 1) with increasing $\mathrm{N}_{2}$ flow during the $\mathrm{H}_{2} / \mathrm{N}_{2}$ plasma process. Our results are in agreement with the Hagen-Rubens relation.

Reports on commercial low-e glass products indicate that they have an emissivity of below 0.45 [25]. Taking into account the obtained results, we deduced that the optimum $\mathrm{H}_{2} / \mathrm{N}_{2}$ with a flow ratio 100/100 in plasma annealing can produce AZO/ITO films with an emissivity of 0.07.

Table 1. Average transmittance in the visible region ( $380-780 \mathrm{~nm}$ ) and emissivity of the $\mathrm{H}_{2} / \mathrm{N}_{2}$ plasma processed AZO/ITO films.

\begin{tabular}{cccc}
\hline $\mathbf{H}_{\mathbf{2}} / \mathbf{N}_{\mathbf{2}}$ Flow Ratio & $\mathbf{1 0 0} \mathbf{~ s c c m} / \mathbf{0 ~} \mathbf{~ c c m}$ & $\mathbf{1 0 0} \mathbf{~ s c c m} / \mathbf{5 0 ~} \mathbf{~ s c c m}$ & $\mathbf{1 0 0} \mathbf{~ s c c m} / \mathbf{1 0 0} \mathbf{~ s c c m ~}$ \\
\hline Emissivity & 0.10 & 0.08 & 0.07 \\
$\begin{array}{c}\text { Average transmittance in the visible } \\
(380-780 \mathrm{~nm}) \text { region (\%) }\end{array}$ & $80 \%$ & $80 \%$ & $80 \%$ \\
\hline
\end{tabular}

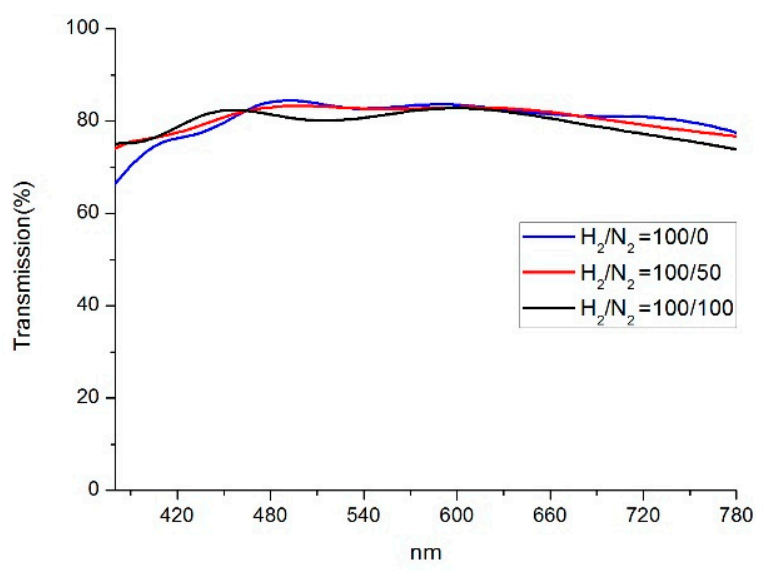

Figure 4. Transmission spectra of the $\mathrm{H}_{2} / \mathrm{N}_{2}$ plasma with different $\mathrm{N}_{2}$ flow processed AZO/ITO films.

\section{Conclusions}

In this study AZO/ITO films were post-annealed in $\mathrm{H}_{2} / \mathrm{N}_{2}$ plasma at different $\mathrm{N}_{2}$ flows. Experiment results showed that the $\mathrm{N}_{2}$ flow in $\mathrm{H}_{2} / \mathrm{N}_{2}$ plasma annealing of $\mathrm{AZO} / \mathrm{ITO}$ films affects the microstructure and electrical behavior of AZO/ITO films. The crystal grains grow and the electrical resistivity and emissivity decrease for $\mathrm{H}_{2} / \mathrm{N}_{2}$ plasma annealed AZO/ITO films as $\mathrm{N}_{2}$ flow is raised during plasma treatment. The average transmittance in visible wavelengths of all plasma treated AZO/ITO films was about $80 \%$. The decreasing of the electrical resistivity of the AZO/ITO films with increasing $\mathrm{N}_{2}$ flow during the $\mathrm{H}_{2} / \mathrm{N}_{2}$ plasma process could be ascribed to the replacement of $\mathrm{Zn}$ ions with $\mathrm{Al}$ ions and the increase in grain size for the AZO/ITO films. The optimized flow ratio for $\mathrm{H}_{2} / \mathrm{N}_{2}$ plasma treatment was found to be 100/100. The $\mathrm{H}_{2} / \mathrm{N}_{2}$ (with a 100/100 flow ratio) plasma annealed AZO/ITO films were able to reach an emissivity of 0.07 and a visible transmittance of $80 \%$, which can be applied to low-e glass.

Author Contributions: S.-C.C. designed and supervised this study and wrote the manuscript with contributions from other co-author. S.-C.C. and H.-T.C. performed the AZO/ITO sample measurement and analysis.

Funding: The authors would like to thank the Ministry of Science and Technology, Taiwan, for their financial support under the grant numbers MOST 105-2221-E-168-010 and MOST 106-2221-E-168-021. This work was partially supported by the Green Energy Technology Research Center. 
Conflicts of Interest: The authors declare no conflict of interest.

\section{References}

1. Kamalisarvestani, M.; Saidur, R.; Mekhilef, S.; Javadi, F.S. Performance, materials and coating technologies of thermochromic thin films on smart windows. Renew. Sustain. Energy Rev. 2013, 26, 353-364. [CrossRef]

2. Rezaei, S.D.; Shannigrahi, S.; Ramakrishna, S. A review of conventional, advanced, and smart glazing technologies and materials for improving indoor environment. Sol. Energy. Mater. Sol. Cells 2017, 159, $26-51$. [CrossRef]

3. Karlsson, B.; Valkonen, E.; Karlsson, T.; Ribbing, C.-G. Materials for solar-transmitting heat-reflecting coatings. Thin Solid Films 1981, 86, 91-98. [CrossRef]

4. Yuste, M.; Galindo, R.E.; Carvalho, S.; Albella, J.M.; Sánchez, O. Improving the visible transmittance of low-e titanium nitride based coatings for solar thermal applications. Appl. Surf. Sci. 2011, 258, 1784-1788. [CrossRef]

5. Ando, E.; Suzuki, S.; Aomine, N.; Miyazaki, M.; Tada, M. Sputtered silver-based low-emissivity coatings with high moisture durability. Vacuum 2000, 59, 792-799. [CrossRef]

6. Ding, G.; Clavero, C. Silver-based low-emissivity coating technology for energy-saving window applications. In Modern Technologies for Creating the Thin-Film Systems and Coatings, 1st ed.; Nikitenkov, N., Ed.; InTechOpen: London, UK, 2017; pp. 418-422.

7. Yun, J.H.; Kim, J. Double transparent conducting oxide films for photoelectric devices. Mater. Lett. 2012, 70, 4-6. [CrossRef]

8. Mahmood, K.; Munir, R.; Kang, H.W.; Sung, H.J. An atmospheric pressure-based electrospraying route to fabricate the multi-applications bilayer (AZO/ITO) TCO films. RSC Adv. 2013, 3, 25741-25751. [CrossRef]

9. Sun, K.; Tang, X.F.; Yang, C.; Jin, D. Preparation and performance of low-emissivity Al-doped ZnO films for energy-saving glass. Ceram. Int. 2018, 44, 19597-19602. [CrossRef]

10. Kim, H.; Gilmore, C.M.; Horwitz, J.S.; Piqué, A.; Murata, H.; Kushto, G.P.; Schlaf, R.; Kafafi, Z.H.; Chrisey, D.B. Transparent conducting aluminum-doped zinc oxide thin films for organic light-emitting devices. Appl. Phys. Lett. 2000, 76, 259-261. [CrossRef]

11. Sima, C.; Grigoriu, C.; Antohe, S. Comparison of the dye-sensitized solar cells performances based on transparent conductive ITO and FTO. Thin Solid Films 2010, 519, 595-597. [CrossRef]

12. Ayachi, B.; Aviles, T.; Vilcot, J.P.; Sion, C. Rapid thermal annealing effect on the spatial resistivity distribution of AZO thin films deposited by pulsed-direct-current sputtering for solar cells applications. Appl. Surf. Sci. 2016, 366, 53-58. [CrossRef]

13. Hagen, E.; Rubens, H. Über Beziehungen des Reflexions- und Emissionsvermögens der Metalle zu ihrem elektrischen Leitvermögen. Ann. Phys. 1903, 11, 873-901. [CrossRef]

14. Jiang, Q.J.; Lu, J.G.; Yuan, Y.L.; Sun, L.W.; Wang, X.; Wen, Z.; Ye, Z.Z.; Xiao, D.; Ge, H.Z.; Zhao, Y. Tailoring the morphology, optical and electrical properties of DC-sputtered $\mathrm{ZnO}: \mathrm{Al}$ films by post thermal and plasma treatments. Mater. Lett. 2013, 106, 125-128. [CrossRef]

15. Chang, H.P.; Wang, F.H.; Wu, J.Y.; Kung, C.Y.; Liu, H.W. Enhanced conductivity of aluminum doped ZnO films by hydrogen plasma treatment. Thin Solid Films 2010, 518, 7445-7449. [CrossRef]

16. Cai, P.F.; You, J.B.; Zhang, X.W.; Dong, J.J.; Yang, X.L.; Yin, Z.G.; Chen, N.F. Enhancement of conductivity and transmittance of $\mathrm{ZnO}$ films by post hydrogen plasma treatment. J. Appl. Phys. 2009, 105, 083713. [CrossRef]

17. Lee, J.; Lim, D.; Yang, K.; Choi, W. Influence of different plasma treatments on electrical and optical properties on sputtered AZO and ITO films. J. Cryst. Growth 2011, 326, 50-57. [CrossRef]

18. Muthitamongkol, P.; Thanachayanont, C.; Samransuksamer, B.; Seawsakul, K.; Horprathum, M.; Eiamchai, P.; Limwichean, S.; Patthanasettakul, V.; Nuntawong, N.; Songsiriritthiguland, P.; et al. The effects of the argon plasma treatments on transparent conductive aluminum-dope zinc oxide thin films prepared by the pulsed DC magnetron sputtering. Mater. Today Proc. 2017, 4, 6248-6253. [CrossRef]

19. Wu, M.; Huang, T.; Jin, C.; Zhuge, L.; Han, Q.; Wu, X. Effect of Multiple Frequency $\mathrm{H}_{2} / \mathrm{Ar}_{\text {Plasma Treatment }}$ on the Optical, Electrical, and Structural Properties of AZO Films. IEEE Trans. Plasma Sci. 2014, 42, 3687-3690. [CrossRef]

20. Chang, S.C. Low pressure $\mathrm{H}_{2} / \mathrm{N}_{2}$ annealing on indium tin oxide film. Microelectron. J. 2007, 38, 1220-1225. [CrossRef] 
21. O'Hanlon, J.F. A User's Guide to Vacuum Technology, 2nd ed.; John Wiley \& Sons, Inc.: Hoboken, NJ, USA, 1989; p. 433.

22. Tong, H.; Deng, Z.; Liu, Z.; Huang, C.; Huang, J.; Lan, H.; Wang, C.; Cao, Y. Effects of post-annealing on structural, optical and electrical properties of Al-doped ZnO thin films. Appl. Surf. Sci. 2011, 257, 4906-4911. [CrossRef]

23. Kittel, C. Introduction to Solid State Physics, 8th ed.; John Wiley \& Sons, Inc.: Hoboken, NJ, USA, $2004 ;$ p. 71.

24. Lu, H.Y.; Chu, S.Y.; Tan, S.S. The characteristics of low-temperature-synthesized ZnS and ZnO nanoparticles. J. Cryst. Growth 2004, 269, 385-391. [CrossRef]

25. Jelle, B.P.; Kalnæs, S.E.; Gao, T. Low-emissivity materials for building applications: A state-of-the-art review and future research perspectives. Energy Build. 2015, 96, 329-356. [CrossRef]

C 2019 by the authors. Licensee MDPI, Basel, Switzerland. This article is an open access article distributed under the terms and conditions of the Creative Commons Attribution (CC BY) license (http://creativecommons.org/licenses/by/4.0/). 